\title{
Effect of seminal plasma removal before cryopreservation of bovine semen obtained by electroejaculation on semen quality and in vitro fertility
}

\author{
Suzane Peres Campanholi ${ }^{\mathrm{a}, *}$, Fabio Morato Monteiro ${ }^{\mathrm{b}}$, \\ Erika Aline Ribeiro Dias ${ }^{\mathrm{b}}$, Maria Eugênia Zerlotti Mercadante ${ }^{\mathrm{b}}$, \\ Claudia Cristina Paro de Paz ${ }^{\mathrm{b}}$, José Antonio Dell'Aqua Junior ${ }^{\mathrm{c}}$, \\ Frederico Ozanam Papa ${ }^{\text {, }}$, Camila de Paula Freitas Dell'Aqua ${ }^{\text {, }}$, \\ Roberta Vantini ${ }^{a}$, Joaquim Mansano Garcia ${ }^{a}$ \\ ${ }^{a}$ Departamento de Reprodução Animal, Universidade Estadual Paulista, FCAV/UNESP, Jaboticabal, São Paulo, Brasil \\ ${ }^{\mathrm{b}}$ Centro APTA Bovinos de Corte, IZ-APTA, Sertãozinho, São Paulo, Brasil \\ ${ }^{\mathrm{c}}$ Departamento de Reprodução Animal e Radiologia Veterinária, Universidade Estadual Paulista, FMVZ/UNESP, \\ Botucatu, São Paulo, Brasil
}

\section{A R T I C L E I N F O}

\section{Article history:}

Received 10 June 2016

Received in revised form 3 October 2016

Accepted 9 October 2016

\section{Keywords:}

Semen

Bull

Cryopreservation

Seminal plasma

Centrifugation

Filtration

\begin{abstract}
A B S T R A C T
Cryopreservation of bull semen is a common biotechnology procedure in cattle breeding. However, when the ejaculate is obtained by electroejaculation, wide variation is observed in the sperm/seminal plasma (SP) ratio that can affect the freezability of semen in this species. The removal of SP may improve the quality of frozen bull semen. The objective of this study was to evaluate the effect of SP removal from the ejaculate on the cryopreservation of semen from 38 Nellore bulls collected by electroejaculation. After collection, the ejaculate was divided into three aliquots: (1) control (N) diluted to a concentration of $60 \times 10^{6}$ spermatozoa/mL and frozen with SP; (2) centrifugation (C) at $\times 600 \mathrm{~g}$ for 10 minutes and the pellet resuspended and frozen at the same concentration as $\mathrm{N}$; and (3) filtration (F) through SpermFilter and sperm recovered and frozen at the same concentration as N. After thawing, sperm kinetics, plasma and acrosome membrane integrity, mitochondrial membrane potential, oxidative stress, and in vitro fertility were evaluated. Statistical analysis was performed using the SAS 9.2 package, and differences were considered significant when $\mathrm{P}<0.05$. Higher average path velocity and straight-line velocity were observed in the groups submitted to SP removal compared to the control group $(\mathrm{P}<0.01)$. In contrast, filtered samples exhibited higher beat cross frequency, straightness, and linearity compared to the other groups. Plasma membrane integrity was reduced when SP was removed, but lower oxidative stress was observed in groups $\mathrm{C}$ and $\mathrm{F}$ (34.91 $\pm 2.95 \%$ and $31.63 \pm 2.95 \%$, respectively) compared to group $\mathrm{N}(57.39 \pm 2.95 \%)$. However, the percentage of hatched blastocysts was similar in the $\mathrm{N}$ and $\mathrm{F}$ groups $(21.22 \pm 1.05 \%$ and $24.00 \pm 1.05 \%$, respectively) and higher compared to group C $(18.83 \pm 1.05 \%)$. In conclusion, removal of SP by centrifugation for bull semen
\end{abstract}

\footnotetext{
* Corresponding author. Tel.: +55 1699734 4754; fax: +55 163203 1226.

E-mail address: supc@hotmail.com (S.P. Campanholi).
} 
freezing reduced the rate of in vitro-produced embryos, whereas filtration of prefrozen semen was found to be an efficient alternative in terms of semen freezability and in vitro production of bovine embryos.

(C) 2016 Elsevier Inc. All rights reserved.

\section{Introduction}

Artificial insemination (AI) is the first generation of animal reproduction biotechnology that had a major impact on animal breeding. By means of AI, a single ejaculate of a bull is used for the insemination of various females, which could not have been possible without sperm cryopreservation [1]. Although bull semen has been cryopreserved for AI for over half a century [2], many of the protocols used are still empirical, with the number of spermatozoa that do not survive the freezing process being considerable and those that do survive being affected structurally or functionally after thawing [3]. In general, many of the strategies tested to achieve successful cryopreservation do not involve the spermatozoon itself but the medium in which it is stored [4].

The fluid that is added to spermatozoa during epididymal transport and ejaculation is called seminal plasma (SP) and is produced by the epididymis and accessory sex glands [5]. Despite several reports of its beneficial effect on spermatozoa, SP has also been described to cause sperm damage [6], an effect that is intimately related to the duration of contact between sperm and SP [7]. During natural mating, spermatozoa remain in contact with SP for a relatively short time, whereas they can stay in contact for hours, or even a day, with diluted SP during semen processing for cryopreservation [5]. Furthermore, in bulls reared in the field, semen is collected by electroejaculation. The ejaculates obtained by this method differ in terms of the quantity and quality of SP from those obtained using artificial vagina, a fact that considerably alters the SP/sperm ratio in semen $[8,9]$.

The composition of SP shows high individual variability in Nellore bulls [10], a fact that results in different responses of the animals to sperm cryopreservation [11,12]. However, the main components of SP (on a weight basis) are proteins, which are considered the predominant modulator of sperm function [13]. Some proteins participate in the regulation of cholesterol and phospholipid efflux from the sperm membrane. This process is concentration and time dependent, and continuous exposure of spermatozoa to SP may therefore damage their membrane [6,14]. This fact can render the spermatozoon more vulnerable to cryopreservation [7] or cause premature post-thaw capacitation, affecting the process of fertilization [15]. In bulls, relative abundance of SP proteins that are positively associated with low fertility has been reported [16-18].

The technique generally used for the removal of SP is centrifugation; however, its intensity and duration can negatively interfere with sperm motility and plasma membrane integrity [19]. Another easily applied separation method is the SpermFilter (Ceafepe Tecnologia Veterinária Ind., Sorocaba, São Paulo, Brazil) proposed by Alvarenga et al. [20]. This method consists of a synthetic hydrophilic membrane filter with a pore size that permits the passage of SP, while retaining only spermatozoa. In stallions, this filter has been shown to be as efficient as centrifugation in the removal of SP and has the advantage of greater practicality and a lower rate of sperm loss [19].

In view of the aforementioned considerations, it is believed that the cryopreservation of bull ejaculates obtained by electroejaculation may be compromised by the deleterious action of SP and that techniques of SP removal improve the quality of cryopreserved sperm in cattle. Centrifugation is commonly used for this purpose but can cause substantial cell injury, and filtration emerges as an alternative to obtain better results. Because no study has so far applied filtration to SP removal in bulls, the objective of the present study was to evaluate the effect of the removal of SP from the ejaculate by centrifugation and filtration on the cryopreservation of bull semen.

\section{Material and methods}

\subsection{Ethics committee}

The study was approved by the Ethics Committee on Animal Use of FCAV/UNESP, Jaboticabal, on June 6, 2014 (Protocol No. 009713/14).

\subsection{Semen collection}

Thirty-eight Nellore (Bos taurus indicus) bulls aged 2 to 6 years belonging to Centro APTA Bovinos de Corte, a research unit of the Instituto de Zootecnia, Sertãozinho, São Paulo, Brazil, were used. The bulls were maintained on pasture, with water and mineral salt available ad libitum, and evaluated regarding the normality of andrologic parameters before the study according to the recommendations of the Brazilian College of Animal Reproduction (mass motility: $\geq 3$; sperm motility: $\geq 60 \%$; concentration: 350 million spermatozoa/mL; total number of spermatozoa in the ejaculate: 3 to 5 billion; morphologically normal spermatozoa: $>70 \%$; major sperm defects: $\leq 10 \%$; minor sperm defects: $\leq 20 \%$; major individual defects: $\leq 5 \%$; minor individual defects: $\leq 10 \%$ ) [21]. Only one ejaculate was collected per bull with an Autojac electroejaculator (Neovet, Uberaba, Brazil) in the manual mode, totaling 38 ejaculates.

\subsection{Experimental groups}

After collection, each ejaculate was divided equally into three aliquots to compare three techniques performed before sperm cryopreservation. The control group (group N) was submitted to conventional cryopreservation without the separation of SP. The semen sample was diluted conventionally to a final concentration of $60 \times 10^{6}$ spermatozoa/mL in BotuBov diluent (BotuPharma, Botucatu, Brazil) containing $7 \%$ glycerol as cryoprotectant. In the centrifugation group (group C), SP was separated by 
centrifugation. The semen sample was diluted 1:4 in BotuBov without cryoprotectant and centrifuged in a Baby II centrifuge (Fanem, São Paulo, Brazil) at $\times 600 \mathrm{~g}$ for 10 minutes at room temperature according to Dell'aqua Jr. et al. [22]. After centrifugation, the supernatant was discarded, and the sediment was resuspended in BotuBov at the same concentration as used for group $\mathrm{N}$. In the filtration group (group F), SP was separated by filtration. For this purpose, the third aliquot of the ejaculate was diluted $1: 4$ in BotuBov without cryoprotectant, and the SP was filtered through the SpermFilter device (BotuPharma/Pat req. US2010/0099075) at room temperature. The spermatozoa retained on the filter were resuspended in BotuBov at the same concentration as used for group $\mathrm{N}$. In groups $\mathrm{C}$ and $\mathrm{F}$, a Neubauer chamber was used to verify the sperm concentration after centrifugation and filtration and to adjust the final dilution of the semen samples to the same concentration as used for group $\mathrm{N}$. The three groups were concomitantly submitted to the respective technique, and each treatment in the respective group was always performed by the same technician.

\subsection{Cryopreservation}

Immediately after collection and processing, the semen samples of the three groups were loaded into $0.5-\mathrm{mL}$ straws at room temperature to a final concentration of 60 $\times 10^{6}$ spermatozoa/mL. For refrigeration and freezing, a programmable semen cryopreservation system was used (TK 4000, Uberaba, Brazil). The device was set to a cooling rate of $-0.25^{\circ} \mathrm{C} / \mathrm{min}$ from room temperature $\left(25^{\circ} \mathrm{C}\right)$ until a temperature of $5{ }^{\circ} \mathrm{C}$ was reached. After stabilization at $5{ }^{\circ} \mathrm{C}$ for 4 hours, freezing was performed at $-20^{\circ} \mathrm{C} / \mathrm{min}$ until a temperature of $-120{ }^{\circ} \mathrm{C}$ was reached, when the straws were directly placed in liquid nitrogen $\left(-196^{\circ} \mathrm{C}\right)$ and stored until the time of post-thaw analysis. All straws of the experimental groups were concomitantly submitted to the cryopreservation steps described.

\subsection{Post-thaw evaluations}

Two straws from the same bull of each group were used for each post-thaw analysis to rule out straw effects. In all groups, the straws were thawed in a water bath at $37^{\circ} \mathrm{C}$ for 30 seconds. The following post-thaw evaluations were performed: computer-assisted sperm analysis (CASA) for the evaluation of sperm kinetics, evaluation of plasma and acrosome membrane integrity, mitochondrial membrane potential and oxidative stress by flow cytometry, and evaluation of fertilizing capacity of sperm based on the result of in vitro embryo production (IVEP).

\subsubsection{Computer-assisted sperm analysis}

For the evaluation of sperm kinetics by CASA, $10 \mu \mathrm{L}$ of the semen sample was placed in a Makler Counting Chamber (Sefi-Medical Instruments Ltd., Haifa, Israel) previously heated to $38{ }^{\circ} \mathrm{C}$, which was inserted into an Ivos-Ultimate apparatus (version 14.0; Hamilton Thorne Biosciences, Beverly, USA). Using the Animal Motility program, the automatic and standardized choice of five fields for analysis was carried out. The CASA setup was preadjusted for the analysis of bovine semen (number of frames: 30; minimum contrast: 60 pixels; minimum cell size: 6 pixels; straightness: 70\%; average path velocity cutoff: $30 \mu \mathrm{m} / \mathrm{s}$; minimum average path velocity: $40 \mu \mathrm{m} / \mathrm{s}$; straight-line velocity cutoff: $20 \mu \mathrm{m} / \mathrm{s}$; nonmotile head intensity: 90; nonmotile head size: 5 pixels; magnification: $\times 1.95$; temperature: $\left.38{ }^{\circ} \mathrm{C}\right)$. The following sperm motility parameters were analyzed: total motility (MT, \%), progressive motility (MP, \%), average path velocity (VAP, $\mu \mathrm{m} / \mathrm{s}$ ), straight-line velocity (VSL, $\mu \mathrm{m} / \mathrm{s}$ ), curvilinear velocity (VCL, $\mu \mathrm{m} / \mathrm{s})$, amplitude of lateral head displacement $(\mu \mathrm{m})$, beat cross frequency (BCF, Hz), straightness (STR, \%), linearity (LIN, \%), and rapid cells (RAP, \%).

\subsubsection{Flow cytometry}

The BD LSR II flow cytometer (Becton Dickinson, Mountain View, CA, USA) equipped with blue (488 nm, $100 \mathrm{~mW}$ ) and red lasers (640 nm, $40 \mathrm{~mW}$ ) was used for flow cytometry. The data were analyzed using the program of the same manufacturer (BD FACSDiva Software v6.1).

The following probes were used for the evaluation of plasma and acrosome membrane integrity: propidium iodide (PI, P4170; Sigma Chemical Company, St. Louis, MO, USA), fluorescein isothiocyanate-conjugated Pisum sativum agglutinin (L0770, Sigma) and Hoechst 33342 (H342; 14533, Sigma). A $200-\mu \mathrm{L}$ semen sample diluted in tyrode albumin lactate pyruvate (TALP) medium to a concentration of $10 \times 10^{6}$ spermatozoa/mL was mixed with $50-\mu \mathrm{L}$ H342 $(100 \mu \mathrm{g} / \mathrm{mL}), 50-\mu \mathrm{L}$ PI $(50 \mu \mathrm{g} / \mathrm{mL})$, and $0.5-\mu \mathrm{L}$ fluorescein isothiocyanate-conjugated Pisum sativum agglutinin $(2 \mathrm{mg} / \mathrm{mL})$. The samples were homogenized and incubated for 15 minutes at $37^{\circ} \mathrm{C}$ protected from light for subsequent analysis according to Freitas Dell'Aqua et al. [23]. Four subpopulations were identified in this analysis: damaged plasma membrane and intact acrosome (DPMIA), damaged plasma and acrosome membranes (DPAM), intact plasma and acrosomes membrane (IPAM), and intact plasma membrane and damaged acrosome (IPMDA).

The mitochondrial membrane potential was evaluated using lipophilic cationic carbocyanine dye (JC-1, T3168; Molecular Probes, Eugene, OR, USA) and H342. For this purpose, a 200- $\mu \mathrm{L}$ semen sample diluted in TALP to a concentration of $10 \times 10^{6}$ spermatozoa/mL was mixed with $50-\mu \mathrm{L} \mathrm{H} 342(100 \mu \mathrm{g} / \mathrm{mL})$ and $10-\mu \mathrm{L} \mathrm{JC}-1(10 \mu \mathrm{g} / \mathrm{mL})$. The samples were homogenized and incubated for 15 minutes at $37^{\circ} \mathrm{C}$ protected from light for subsequent analysis. Three subpopulations were identified: high, medium, and low mitochondrial membrane potential.

For the evaluation of oxidative stress by the production of reactive oxygen species (ROS), 2',7'-dichlorodihydrofluorescein diacetate (DCFDA; D6883, Sigma), PI, and H342 were used. A $500-\mu \mathrm{L}$ semen sample diluted in TALP to a concentration of $1 \times 10^{6}$ spermatozoa/mL was mixed with $0.5-\mu \mathrm{L}$ DCFDA (final concentration of $20 \mu \mathrm{M}$ ), $50 \mu \mathrm{L}$ PI $(50 \mu \mathrm{g} / \mathrm{mL})$, and $50 \mu \mathrm{L} \mathrm{H} 342(100 \mu \mathrm{g} / \mathrm{mL})$. The samples were homogenized and incubated for 60 minutes at room temperature protected from light for subsequent analysis according to Guthrie and Welch [24]. Two subpopulations were identified in this analysis: ROS-positive total cells and ROS-positive intact cells. 


\subsubsection{In vitro embryo production}

In view of the high cost of IVEP, this assessment was performed with 31 randomly selected bulls. Only one IVPE of each bull was performed. For each bull, an average of $405 \pm 45$ oocytes was divided among the three groups (N, C, and F). Six fertilization droplets per bull were used per group (N, C, and F), resulting in 18 fertilization droplets per bull. Each fertilization droplet contained 20 to 25 oocytes.

Bovine cumulus-oocyte complexes (COCs) were collected by follicular aspiration of ovaries obtained from a local slaughterhouse. COCs with homogenous cytoplasm and at least three layers of compact cumulus cells were selected. The selected COCs were washed twice in TCM-199 medium (Gibco BRL, Grand Island, NY, USA) supplemented with $5 \mathrm{mM}$ sodium bicarbonate, $10 \mathrm{mM}$ HEPES sodium salt (Sigma), 10 mM HEPES free acid (Sigma), 10\% fetal bovine serum (FBS; Cripion, Andradina, SP, Brazil), $0.20 \mathrm{mM}$ sodium pyruvate, and $83.4-\mu \mathrm{g} / \mathrm{mL}$ amikacin (Instituto Biochimico, Rio de Janeiro, Brazil), and once in TCM-199 maturation medium (Gibco BRL) buffered with $25 \mathrm{mM}$ sodium bicarbonate and supplemented with 10\% FBS (Cripion), $1.0 \mu \mathrm{g} / \mathrm{mL}$ FSH (Folltropin; Bioniche Animal Health, Belleville, Canada), $50 \mu \mathrm{g} / \mathrm{mL}$ hCG (Vetercor; Intervet, São Paulo, Brazil), $1.0 \mu \mathrm{g} / \mathrm{mL}$ estradiol, $0.20 \mathrm{mM}$ sodium pyruvate, and $83.4 \mu \mathrm{g} / \mathrm{mL}$ amikacin (Instituto Biochimico), according to Gaspar et al. [25]. Groups of 20 to 25 COCs were cultured in $100-\mu \mathrm{L}$ microdroplets of maturation medium under sterile mineral oil for 24 hours at $38.5^{\circ} \mathrm{C}$ in a humidified atmosphere of $5 \% \mathrm{CO}_{2}$ in air.

After maturation, the groups of COCs were washed and transferred to $100-\mu \mathrm{L}$ droplets (six fertilization droplets per group, resulting in 18 fertilization droplets per bull, containing 20 to 25 oocytes per droplet) of TALP-IVF medium supplemented with $6-\mathrm{mg} / \mathrm{mL}$ BSA - fatty acid free and low endotoxin, $10-\mu \mathrm{g} / \mathrm{mL}$ heparin, $18 \mu \mathrm{M}$ penicillamine, $10 \mu \mathrm{M}$ hypotaurine, and $1.8 \mu \mathrm{M}$ epinephrine, under sterile mineral oil. The semen was thawed, transferred to a tube containing a discontinuous gradient of $45 \%$ and $90 \%$ Percoll, and centrifuged at $\times 3240 \mathrm{~g}$ for 5 minutes in a Universal $32 \mathrm{R}$ centrifuge (Hettich, Tuttlingen, Germany) at room temperature. The supernatant was discarded, and the sediment was resuspended in $500-\mu \mathrm{L}$ supplemented TALP-IVF medium. Sperm cells were again sedimented by centrifugation at $\times 900 \mathrm{~g}$ for 5 minutes at room temperature. The volume of the sediment was adjusted to a final concentration of approximately $5 \times 10^{3}$ spermatozoa per oocyte. Semen and COCs were cocultured for 18 to 22 hours at $38.5{ }^{\circ} \mathrm{C}$ in a humidified atmosphere of $5 \% \mathrm{CO}_{2}$ in air.

After fertilization, the presumed zygotes were denuded of cumulus cells by successive pipetting, transferred to four-well cell culture plates containing synthetic oviduct fluid (SOF) supplemented with 2.5\% FBS and 5-mg/mL BSA - fatty acid free and low endotoxin, and cultured at $38.5{ }^{\circ} \mathrm{C}$ in a humidified atmosphere of $5 \% \mathrm{CO}_{2}$ in air. Because a four-well culture plate was used, $500-\mu \mathrm{L}$ supplemented SOF medium was added to each well, and exchange of the medium during culture was not necessary. The cleavage rate was evaluated on Day 2 (D2) after fertilization. The fertilization rate in each group was calculated based on the total number of oocytes. The rate of blastocyst formation was evaluated on Day 7 (D7) after fertilization and only hatched blastocysts were evaluated on Day 9 (D9).

\subsection{Statistical analysis}

After testing and adjustment for normality of distribution and homoscedasticity of variance, the data were analyzed using the generalized linear model procedure of the Statistical Analysis Software (SAS Institute, Inc., Cary, NC, USA). Treatment least-square means were compared by the Tukey test. The bull effect was included in the model as a random effect and the effect of treatment as a fixed effect. A level of significance of $5 \%$ was adopted. Correlation analyses were performed using the SAS CORR procedure (SAS Institute, Inc., Cary, NC, USA).

\section{Results}

Table 1 provides the results of evaluation of sperm kinetics by CASA and of sperm plasma membrane and acrosome integrity, mitochondrial potential, and oxidative stress by flow cytometry.

Post-thaw evaluation of sperm kinetics revealed no difference in MT, MP, VCL, amplitude of lateral head displacement, or RAP between groups. However, VAP and VSL were higher $(\mathrm{P}<0.05)$ in the absence of SP, irrespective

\section{Table 1}

Mean and SEM of post-thaw kinetic parameters of bovine $(\mathrm{n}=38)$ sperm cells evaluated by CASA and flow cytometry in the control (semen frozen with SP), centrifugation (semen centrifuged at $\times 600 \mathrm{~g}$ for 10 minutes and frozen without SP), and filtration (semen filtered through SpermFilter and frozen without SP) groups.

\begin{tabular}{lcccc}
\hline Parameter & Control $(\mathrm{N})$ & Centrifugation $(\mathrm{C})$ & Filtration $(\mathrm{F})$ & SEM \\
\hline MT $(\%)$ & 54.02 & 53.51 & 50.72 & 1.77 \\
MP $(\%)$ & 41.29 & 42.18 & 41.56 & 1.40 \\
VAP $(\mu \mathrm{m} / \mathrm{s})$ & $79.65^{\mathrm{b}}$ & $84.35^{\mathrm{a}}$ & $86.00^{\mathrm{a}}$ & 1.13 \\
VSL $(\mu \mathrm{m} / \mathrm{s})$ & $66.97^{\mathrm{b}}$ & $71.06^{\mathrm{a}}$ & $74.15^{\mathrm{a}}$ & 0.92 \\
VCL $(\mu \mathrm{m} / \mathrm{s})$ & 133.61 & 139.59 & 138.46 & 2.12 \\
ALH $(\mu \mathrm{m})$ & 5.70 & 5.79 & 5.56 & 0.08 \\
BCF $(\mathrm{Hz})$ & $32.20^{\mathrm{b}}$ & $31.96^{\mathrm{b}}$ & $33.80^{\mathrm{a}}$ & 0.35 \\
STR $(\%)$ & $84.32^{\mathrm{b}}$ & $84.48^{\mathrm{b}}$ & $86.16^{\mathrm{a}}$ & 0.47 \\
LIN $(\%)$ & $52.70^{\mathrm{b}}$ & $53.40^{\mathrm{b}}$ & $55.54^{\mathrm{a}}$ & 0.50 \\
RAP $(\%)$ & 49.32 & 51.32 & 48.70 & 1.80 \\
IPAM $(\%)$ & $23.88^{\mathrm{a}}$ & $22.45^{\mathrm{a}}$ & $18.04^{\mathrm{b}}$ & 0.70 \\
DPAM (\%) & $30.61^{\mathrm{b}}$ & $38.46^{\mathrm{a}}$ & $39.34^{\mathrm{a}}$ & 0.98 \\
DPMIA (\%) & $45.19^{\mathrm{a}}$ & $38.49^{\mathrm{b}}$ & $42.20^{\mathrm{a}}$ & 0.99 \\
IPMDA (\%) & $0.31^{\mathrm{b}}$ & $0.59^{\mathrm{a}}$ & $0.40^{\mathrm{a}, \mathrm{b}}$ & 0.06 \\
HMP (\%) & 24.28 & 28.22 & 27.38 & 1.68 \\
MMP $(\%)$ & 42.39 & 37.73 & 38.91 & 1.85 \\
LMP $(\%)$ & 33.32 & 34.03 & 33.70 & 2.06 \\
ROS+ TC (\%) & $57.39^{\mathrm{a}}$ & $34.91^{\mathrm{b}}$ & $31.63^{\mathrm{b}}$ & 2.95 \\
ROS+ IC $(\%)$ & $81.62^{\mathrm{a}}$ & $72.54^{\mathrm{b}}$ & $70.64^{\mathrm{b}}$ & 2.00
\end{tabular}

a,b Means in the same row followed by different superscripts letter differ significantly $(\mathrm{P}<0.05)$ from each other.

Abbreviations: ALH, amplitude of lateral head displacement; BCF, beat cross frequency; DPAM, damaged plasma and acrosome membranes; DPMIA, damaged plasma membrane and intact acrosome; HMP, high mitochondrial membrane potential; IPAM, intact plasma and acrosome membranes; IPMDA, intact plasma membrane and damaged acrosome LIN, linearity; LMP, low mitochondrial membrane potential; MMP, medium mitochondrial membrane potential; MP, progressive motility; MT, total motility; RAP, rapid cells; ROS, reactive oxygen species; ROS + IC ROS-positive intact cells; ROS + TC, ROS-positive total cells; SEM, standard error of the mean; SP, seminal plasma; STR, straightness; VAP, average path velocity; VCL, curvilinear velocity; VSL, straight-line velocity. 
of the method used for its removal, and BCF, STR, and LIN were higher when SP was removed by filtration. A high correlation was observed between VAP and VSL $(r=0.90)$, and LIN was positively correlated with BCF $(r=0.78)$ and with STR $(r=0.84)$.

The percentage of sperm with intact plasma and acrosome membranes was lower in group $\mathrm{F}$ compared to groups $\mathrm{N}$ and $\mathrm{C}$, which did not differ from one another. Regarding the percentage of sperm in which both membranes were damaged, this percentage was lower in group $\mathrm{N}$ than in groups $\mathrm{C}$ and $\mathrm{F}$, which did not differ from one another. Furthermore, a lower percentage of sperm in which only the plasma membrane was damaged was observed in group $\mathrm{C}$, whereas group $\mathrm{N}$ did not differ from group $\mathrm{F}$. With respect to the sperm subpopulation in which only the acrosome membrane was damaged, group $\mathrm{C}$ exhibited a significantly higher percentage than group $\mathrm{N}$, whereas group $\mathrm{F}$ did not differ from groups $\mathrm{C}$ or $\mathrm{N}$. The DPAM was negatively correlated with DPMIA $(r=-0.69)$ and with IPAM $(r=-0.49)$.

There was no difference in post-thaw mitochondrial membrane potential between groups. However, the evaluation of oxidative stress showed a larger number of ROSpositive total and intact cells in group $\mathrm{N}$ compared to the groups without SP. This characteristic was not altered by the method used for the removal of SP. The ROS-positive total cells showed only a low correlation with DPMIA $(r=0.24)$.

Table 2 provides the rates of development of in vitroproduced embryos using semen from groups N, C, and F. The cleavage rate of embryos did not differ between groups. With respect to development until the blastocyst stage and blastocyst hatching, higher rates were observed for groups $\mathrm{F}$ and $\mathrm{N}$, which did not differ from one another. However, group $C$, which exhibited a lower rate until the blastocyst stage than groups $\mathrm{N}$ and $\mathrm{F}$, did not differ from group $\mathrm{N}$ on D9 (rate of hatching). The rate of blastocyst formation on D7 showed a low correlation $(r=0.22)$ with IPMDA, and D9 was positively correlated with D7 $(r=0.75)$.

\section{Discussion}

The removal of SP for semen cryopreservation is used in different species, including horses [26], pigs [27], and dogs [28]. Because the ejaculate of cattle shows a low sperm/SP ratio, the removal of SP is not an elective technique for sperm processing in this species. However, this ratio changes when the semen is collected by electroejaculation because a higher volume of semen containing a lower sperm concentration is obtained when this method is applied [29].

In cattle, bull semen collected by electroejaculation varies widely in terms of freezability outcome. This diversity may be due to differences in the composition of SP as a result of the semen collection method. In Brahman bulls, SP recovered by artificial vagina has been shown to contain 21 proteins, most of them of epididymal origin, whereas that collected by electroejaculation contained 26 proteins, most of them derived from the accessory sex glands [30]. Other authors reported the presence of 46 proteins in SP of Bos indicus bulls collected by electroejaculation [31]. Furthermore, SP behaves differently between individuals of the same species because of individual variations in its composition [10].

Sperm motility is routinely evaluated in the analysis of fertility potential because it is an index of the viability and structural integrity of spermatozoa [32]. A deleterious effect of SP on bovine sperm resulting from the increased release of L-amino acid oxidase and reduced sperm motility has been reported when cryopreservation was performed in the presence of SP [11]. In the present study, analysis of post-thaw sperm kinetics showed higher VAP and VSL in the groups without SP (groups C and F) and higher BCF, STR, and LIN after removal of SP by filtration (group F). The viscosity of SP itself may have contributed to reduce VAP and VSL in the control group. VAP represents the average velocity of the sperm path and depends on the lateral movement of the sperm head, and VSL represents the average velocity as a function of a straight line established between the first and last points of the sperm path [33]. In bulls, a high correlation $(r=0.97)$ is observed between these parameters (VAP, VSL, BCF, STR, and LIN) and in vivo fertility [34]. In the present study, better rates of embryonic development were found in the group that exhibited high values of these parameters (group F).

In a similar study, Ramires Neto et al. [19] evaluated the effect of removal of SP by filtration and centrifugation on frozen stallion semen. These authors also found no difference in sperm kinetics (MT, MP, VCL, and RAP) when SP was removed, and they reported semen filtration was as efficient as centrifugation at $\times 600 \mathrm{~g}$ for 10 minutes in the maintenance of sperm viability. A study using equine epididymal semen previously incubated with BotuSêmen (BotuPharma, Botucatu, Brazil) or SP and centrifuged at $\times 600 \mathrm{~g}$ for 10 minutes before cryopreservation reported no difference in MT, MP, or RAP between the two groups during post-thaw evaluation [35].

Table 2

Rate of development (mean and standard error of the mean) of in vitro-produced bovine embryos using semen of the control, centrifugation, and filtration groups.

\begin{tabular}{llll}
\hline Group & Total oocytes & Rate of development (\%) & \\
\cline { 2 - 4 } & & Cleavage (D2) $^{\mathrm{c}}$ & Blastocyst (D7) $^{\mathrm{c}}$ \\
\hline Control (N) & 4570 & $82.11 \pm 0.83$ & $31.30 \pm 1.07^{\mathrm{a}}$ \\
Centrifugation (C) & 4535 & $82.05 \pm 0.83$ & $26.55 \pm 1.07^{\mathrm{b}}$ \\
Filtration (F) & 4507 & $84.01 \pm 0.83$ & $32.30 \pm 1.07^{\mathrm{a}}$ \\
\hline
\end{tabular}

\footnotetext{
${ }^{\mathrm{a}, \mathrm{b}}$ Means in the same column followed by different superscript letters differ significantly $(\mathrm{P}<0.05)$ from each other.

${ }^{c}$ Percentage based on the total number of oocytes.
} 
Several studies have demonstrated the importance of the plasma and acrosome membranes for sperm capacitation and acrosomal reaction, processes that are essential for fertilization [36-38], and different SP proteins exert an effect on these processes [39-42]. When semen is collected by electroejaculation, higher amounts of binder of sperm (BSP) proteins, which stimulate cholesterol and phospholipid efflux from the sperm membrane, are found in SP [43]. However, the dilution of semen in extender containing egg yolk offers protection to sperm through the interaction of the low-density lipoprotein fraction of the diluent with the BSPs present in SP. This interaction prevents the binding of these proteins to sperm that can cause damage to the sperm membrane by the continuous stimulation of cholesterol and phospholipid efflux [6]. In addition to these mechanisms, the fact that group $\mathrm{N}$ had not undergone any type of processing before cryopreservation may have contributed to the lower percentage of cells in which the two membranes were damaged (DPAM) and the higher percentage of cells in which the two membranes were intact (IPAM). Analysis revealed a moderate negative correlation between these two parameters $(r=-0.49)$.

The groups submitted to removal of SP (groups C and F) exhibited a higher percentage of the DPAM subpopulation (damaged plasma and acrosome membranes), probably due to the processing of the samples. The percentage of the DPMIA subpopulation, in which only the plasma membrane was damaged, was higher in group $\mathrm{F}$ compared to group $\mathrm{C}$. The handling of the filter for SP removal or resuspension of the spermatozoa during this process may have caused damage to the plasma membrane. The fact that the plasma membrane is the outermost surface of spermatozoa could explain the higher percentage of the DPMIA subpopulation and consequently of the DPAM subpopulation in group F. A high percentage of the DPAM subpopulation and a low percentage of the DPMIA subpopulation were observed in group $\mathrm{C}$, a fact also demonstrated by the negative correlation between these two subpopulations $(r=-0.69)$. The damage caused by the process of centrifugation possibly more severely affected the integrity of the acrosome membrane [44], although no difference in the IPMDA subpopulation was observed between groups $\mathrm{C}$ and $\mathrm{F}$. Centrifugation should be carried out gently and carefully because this technique has been shown to cause sperm damage, reducing sperm motility and fertility [45-48]. Furthermore, sperm not submitted to centrifugation contains a larger number of mobile and viable spermatozoa without acrosome reaction than sperm submitted to centrifugation [49].

Mitochondria are important components of sperm cells because of their physiological function of oxidative phosphorylation for ATP production, which is an essential source of metabolic energy for flagellar beating and, consequently, sperm motility [38]. Regarding mitochondrial membrane potential, no difference was observed between groups as expected, showing that the presence or absence of SP does not alter this parameter. Pasquini et al. [35] also found no difference in this parameter when epididymal semen of stallions was incubated only with SP or BotuSêmen diluent for 15 minutes, followed by centrifugation and cryopreservation. Tanghe et al. [50] reported that the percentage of spermatozoa with high mitochondrial activity evaluated by fluorescence microscopy was moderately correlated with IVF outcome $(0.30<r<0.50)$.

According to Hu et al. [51], the process of semen freezing and thawing alone results in the generation of ROS, which compromises sperm motility, membrane integrity, and fertilizing potential. Spermatozoa and SP possess an antioxidant system that comprises different substances such as taurine, reduced glutathione, glutathione peroxidase, catalase, and superoxide dismutase to prevent oxidative damage. This antioxidant capacity is limited in sperm cells because of the reduced size of the cytoplasmic component that contains the antioxidants [52]. However, it is the relationship between the production and elimination of ROS that determines the effect of oxidative stress on sperm cell metabolism and fertility and not only the presence or absence of antioxidants in semen [53,54]. Some studies on cattle have demonstrated the importance of ROS for sperm capacitation and acrosomal reaction [55,56].

Interestingly, in the present study, higher ROS production was observed in group $\mathrm{N}$ whose semen was cryopreserved in the presence of SP compared to the groups in which cryopreservation was performed without SP. Detailed analysis of ROS-positive cells showed a reduction in the difference between ROS-positive total cells of group $\mathrm{N}$ and groups $\mathrm{C}$ and $\mathrm{F}$ (22.48 and 25.76 percent points, respectively) to 9.08 and 10.98 percent points, respectively, when only intact cells were analyzed, although the difference continued to be significant at the $5 \%$ level. This finding suggests the difference between group $\mathrm{N}$ and the remaining groups to be more expressive because of the larger number of abnormal sperm cells that produce higher quantities of ROS [54]. Removal of $\mathrm{SP}$ in groups $\mathrm{C}$ and $\mathrm{F}$ has probably eliminated part of the abnormal cells, reducing the percentage of cells producing ROS in these groups. Sieme et al. [48] suggested that part of the spermatozoa that are lost during the filtration process because of their binding to the membrane of the filter are of lower quality, and doubts remain whether these spermatozoa are able to fertilize eggs if recovered. According to these authors, sperm loss due to filtration may therefore be less important than the high rate of sperm loss resulting from centrifugation in which even mobile and viable cells remain in the supernatant. In addition, spermatozoa that pass the filter have a head $<2 \mathrm{~mm}$ and are therefore morphologically underdeveloped cells [57]. In cattle, a recent study has shown that the bull factor is responsible for $>86 \%$ of the variation in the total antioxidant capacity of SP, whereas the ejaculate factor contributes only $2 \%$ of this variation [2]. A different result may be obtained when the same analysis is performed in other animals.

With respect to IVEP, the method chosen to evaluate the fertilizing capacity of semen, the conception rates estimated based on the combined data of blastocyst cleavage and formation have been shown to be very similar to the true conception rates observed for the same bulls after a fixedtime AI program, thus permitting the estimation of bull fertility based on the data obtained during IVEP [58]. A study evaluating the effect of SP on the in vitro fertility of cattle showed that sperm frozen in the absence of SP produced more fertilized oocytes, a higher cleavage rate, and a larger number of embryos in the blastocyst stage than semen frozen in the presence of SP [59]. Similarly, in the present 
study, the removal of SP by filtration resulted in high percentages of blastocysts and hatched blastocysts; however, good embryo development rates were also observed in group N whose semen was cryopreserved with SP. Recent studies have demonstrated that many proteins present in bovine SP play an important role in the processes of sperm maturation, protection, capacitation, acrosomal reaction, and fertilization [31,60-62]. However, it appears that the beneficial effects of these substances are not transferred to in vitro embryo development [63].

One hypothesis to explain the higher rates of embryonic development obtained for semen submitted to filtration, despite the higher percentage of sperm with a damaged membrane, is that the discontinuous Percoll gradient performed before in vitro fertilization has selected a population of cells with greater motility and intact plasma and acrosome membranes [64-68], minimizing the difference between groups in the post-thaw evaluation of this parameter. If a larger number of abnormal cells generated a higher quantity of ROS in the control group, it is also possible that the number of these cells has been reduced after passage through the discontinuous Percoll gradients, minimizing the harmful effects of oxidative stress on the embryonic development of group N.

Regarding the group submitted to centrifugation (group C), a possible explanation for the lower rates of embryonic development despite the good results in terms of postthaw sperm kinetics, percentage of sperm with intact plasma and acrosome membranes, and ROS production is the deterioration of sperm at the DNA level during processing for SP removal. Sperm DNA does not exert any function during fertilization as long as the sperm membranes and its organelles remain functionally intact but is very important for early embryonic development when the first divisions and initiation of embryo DNA expression occur $[69,70]$. Damaged sperm DNA shows normal zona pellucida binding characteristics and even normal fertilization and cleavage rates, but apoptosis is induced when the eight-cell embryo stage is reached [71]. The results indicate the occurrence of this event in group $C$ because the cleavage rate was similar to that of the other groups, while embryonic development was compromised. However, we did not perform any analysis of DNA damage.

\subsection{Conclusion}

The removal of SP by centrifugation reduces the rate of in vitro-produced embryos. In contrast, filtration of prefrozen semen was found to be an efficient alternative in terms of freezability and in vitro production of bovine embryos. Further studies on SP removal by filtration using the SpermFilter are needed, especially to evaluate its effect on the in vivo fertility of animals.

\section{Acknowledgments}

The authors thank FAPESP for financial support (grants 2012/05555-8 and 2014/02659-2), CAPES for granting a Master's fellowship, and BotuPharma for kindly providing the products.

\section{References}

[1] Büyükleblebici S, Tuncer PB, Bucak MN, Eken A, Sarıözkan S, Tassdemir $U$, et al. Cryopreservation of bull sperm: effects of extender supplemented with different cryoprotectants and antioxidants on sperm motility, antioxidant capacity and fertility results. Anim Reprod Sci 2014;150:77-83.

[2] Gürler H, Calisici O, Bollwein H. Inter- and intra-individual variability of total antioxidant capacity of bovine seminal plasma and relationships with sperm quality before and after cryopreservation. Anim Reprod Sci 2015;155:99-105.

[3] Nagy S, Hallap T, Johannisson A, Rodriguez-Martinez H. Changes in plasma membrane and acrosome integrity of frozen-thawed bovine spermatozoa during a $4 \mathrm{~h}$ incubation as measured by multicolor flow cytometry. Anim Reprod Sci 2004;80:225-35.

[4] Mocé E, Blanch E, Tomás C, Graham JK. Use of cholesterol in sperm cryopreservation: present moment and perspectives to future. Reprod Domest Anim 2010;45:57-66.

[5] Burroughs CA, Graham JK, Lenz RW, Seidel Jr GE. Seminal plasma effects on sex-sorting bovine sperm. Theriogenology 2013;79: $551-7$.

[6] Bergeron A, Crête MH, Brindle Y, Manjunath P. Low-density lipoprotein fraction from hen's egg yolk decreases the binding of the major proteins of bovine seminal plasma to sperm and prevents lipid efflux from the sperm membrane. Biol Reprod 2004;70:708-17.

[7] Manjunath P, Bergeron A, Lefebvre J, Fan J. Seminal plasma proteins: functions and interaction with protective agents during semen preservation. Soc Reprod Fertil Suppl 2007;65:217-28.

[8] Austin JW, Hupp EW, Murphree RL. Comparison of quality of bull semen collected in the artificial vagina and by eletroejaculation. J Dairy Sci 1961;44:2292-7.

[9] Tibary A, Graham EF, Asri A, Boukhliq R, Deyo R. Effect of dialysis or centrifugation on post-thaw motility and fertility of Santa Gertrudis bull semen collected by electroejaculation. Theriogenology 1990;33: 733-9.

[10] Assumpção TI, Torres Júnior RAA, Sousa MV, Ricart CAO. Correlation between fertility and levels of protein, sugar and free amino acids in seminal plasma of Nelore bulls. Arq Bras Med Vet Zootec 2005;57: 55-61.

[11] Martinus RD, Molan PC, Shannon P. Deleterious effect of seminal plasma in the cryo-preservation of bovine spermatozoa. New Zeal J Agr Res 1991;34:281-5.

[12] Jobim MIM, Oberst ER, Salbego CG, Souza DO, Wald VB, Tramontina F, et al. Two-dimensional polyacrylamide gel electrophoresis of bovine seminal plasma proteins and their relation with semen freezability. Theriogenology 2004:61:255-66.

[13] Leahy T, de Graaf SP. Seminal plasma and its effect on ruminant spermatozoa during processing. Reprod Domest Anim 2012;47:207-13.

[14] Thérien I, Moreau R, Manjunath P. Bovine seminal plasma phospholipid-binding proteins stimulate phospholipid efflux from epididymal sperm. Biol Reprod 1999;61:590-8.

[15] Nauc V, Manjunath P. Radioimmunoassays for bull seminal plasma proteins (BSP-A1/-A2, BSP-A3, and BSP-30-Kilodaltons), and their quantification in seminal plasma and sperm. Biol Reprod 2000;63: 1058-66.

[16] D'Amours O, Frenette G, Fortier M, Leclerc P, Sullivan R. Proteomic comparison of detergent-extracted sperm proteins from bulls with different fertility indexes. Reproduction 2010;139:545-56.

[17] Roncoletta M, Morani EDSC, Esper CR, Barnabe VH, Franceschini PH. Fertility-associated proteins in Nellore bull sperm membranes. Anim Reprod Sci 2006;91:77-87.

[18] Moura AA, Koc H, Chapman DA, Killian GJ. Identification of proteins in the accessory sex gland fluid associated with fertility indexes of dairy bulls: a proteomic approach. J Androl 2006;27:201-11.

[19] Ramires Neto C, Monteiro GA, Soares RF, Pedrazzi C, Dell'aqua Jr JA, Papa FO, et al. Effect of removing seminal plasma using a Sperm Filter on the viability of refrigerated stallion semen. J Equine Vet Sci $2013 ; 33: 40-3$

[20] Alvarenga MA, Melo CM, Magalhães LCO, Papa FO. A new method to concentrate equine sperm. Anim Reprod Sci 2010;121:186-7.

[21] Colégio Brasileiro de Reprodução Animal (CBRA). Manual para exame andrológico e avaliação do sêmen animal. Third edition. Belo Horizonte: CBRA; 2013.

[22] Dell'aqua Jr JA, Papa FO, Alvarenga MA, Zahn FS. Effect of centrifugation and packing system on sperm parameters of equine frozen semen. Anim Reprod Sci 2001;68:324-5.

[23] Freitas-Dell'aqua CP, Guasti PN, Monteiro GA, Maziero RRD, Dell'Aqua Jr JA, Papa FO. Flow cytometric analysis of fertile and subfertile frozen stallion spermatozoa. Anim Reprod Sci 2012;9:941. 
[24] Guthrie HD, Welch GR. Determination of intracellular reactive oxygen species and high mitochondrial membrane potential in Percoll-treated viable boar sperm using fluorescence-activated flow cytometry. J Anim Sci 2006;84:2089-100.

[25] Gaspar RC, Arnold DR, Corrêa CAP, da Rocha Jr CV, Penteado JCT, del Collado $\mathrm{M}$, et al. Oxygen tension affects histone remodeling of in vitro-produced embryos in a bovine model. Theriogenology 2015;83:1408-15.

[26] Loomis PR. Advanced methods for handling and preparation of stallion semen. Vet Clin North Am Equine Pract 2006;22:663-76.

[27] Carvajal G, Cuello C, Ruiz M, Vázquez JM, Martínez EA, Roca J. Effects of centrifugation before freezing on boar sperm cryosurvival. J Androl 2004;25:389-96.

[28] Rijsselaere T, Van Soom A, Maes D, De Kruif A. Effect of centrifugation on in vitro survival of fresh diluted canine spermatozoa. Theriogenology 2002;57:1669-81.

[29] León H, Porras AA, Galina CS, Navarro-Fierro R. Effect of the collection method on semen characteristics of Zebu and European type cattle in the tropics. Theriogenology 1991;36:349-55.

[30] Rego JPA, Moura AA, Nouwens AS, Mcgowan MR, Boe-hansen GB. Seminal plasma protein profiles of ejaculates obtained by internal artificial vagina and electroejaculation in Brahman bulls. Anim Reprod Sci 2015;160:126-37.

[31] Rego JPA, Crisp JM, Moura AA, Nouwens AS, Li Y, Venus B, et al. Seminal plasma proteome of electroejaculated Bos indicus bulls. Anim Reprod Sci 2014;148:1-17.

[32] Verstegen J, Iguer-Ouada M, Onclin K. Computer assisted semen analyzers in andrology research and veterinary practice. Theriogenology 2002;57:149-79.

[33] Matos DL, Araújo AA, Roberto IG, Toniolli R. Análise computadorizada de espermatozoides: revisão de literatura. Rev Bras Reprod Anim 2008;32:225-32.

[34] Farrell PB, Presicce GA, Brockett CC, Foote RH. Quantification of bull sperm characteristics measured by computer-assisted sperm analysis (CASA) and the relationship to fertility. Theriogenology 1998; 49:871-9.

[35] Pasquini DF, Melo CM, Papa FO, Fioratii EG, Landim-Alvarenga FC, Alvarenga MA, et al. Effects of seminal plasma and sperm motility factors on viability of epididymal sperm of stallions. Anim Reprod Sci 2008;107:337-8.

[36] Graham JK, Mocé E. Fertility evaluation of frozen/thawed semen. Theriogenology 2005;64:492-504.

[37] Amann RP, Hammerstedt RH. In vitro evaluation of sperm quality: an opinion. J Androl 1993;14:397-406.

[38] Flesch FM, Gadella BM. Dynamics of the mammalian sperm plasma membrane in the process of fertilization. Biochim Biophys Acta 2000; $1469: 197-235$

[39] Manjunath P, Thérien I. Role of seminal plasma phospholipidbinding proteins in sperm membrane lipid modification that occurs during capacitation. J Reprod Immunol 2002;53:109-19.

[40] Thérien I, Bleau G, Manjunath P. Phosphatidylcholine-binding proteins of bovine seminal plasma modulate capacitation of spermatozoa by heparin. Biol Reprod 1995;52:1372-9.

[41] Thérien I, Soubeyrand S, Manjunath P. Major proteins of bovine seminal plasma modulate sperm capacitation by high-density lipoprotein. Biol Reprod 1997;57:1080-8.

[42] Moura AA, Chapman DA, Koc H, Killian GJ. A comprehensive proteomic analysis of the accessory sex gland fluid from mature Holstein bulls. Anim Reprod Sci 2007;98:169-88.

[43] Sarsaifi K, Vejayan J, Wahid Haron A, Yusoff R, Hani H, Rasoli M, et al. Protein profile and functionality of spermatozoa from two semen collection methods in Bali bulls. Livest Sci 2015;172:96-105.

[44] Risopatrón J, Sanchéz R, Sepúlveda N, Peña P, Villagran E, Miska W. Migration/sedimentation sperm selection method used in bovine in vitro fertilization: comparison with washing/centrifugation. Theriogenology 1996;46:65-73.

[45] Sharma RK, Vemulapalli S, Kohn S, Agarwal A. Effect of centrifuge speed, refrigeration medium, and sperm washing medium on cryopreserved sperm quality after thawing. Syst Biol Reprod Med 1997;39:33-8.

[46] Aurich C. Recent advances in cooled-semen technology. Anim Reprod Sci 2008;107:268-75.

[47] Kareskoski AM, Reilas T, Andersson M, Katila T. Motility and plasma membrane integrity of spermatozoa in fractionated stallion ejaculates after storage. Reprod Domest Anim 2006;41:33-8.

[48] Sieme H, Martinsson G, Rauterberg H, Walter K, Aurich C, Petzoldt R, et al. Application of techniques for sperm selection in fresh and frozen-thawed stallion semen. Reprod Domest Anim 2003:38:134-40.
[49] Len JA, Jenkins JA, Eilts BE, Paccamonti DL, Lyle SK, Hosgood G. Immediate and delayed (after cooling) effects of centrifugation on equine sperm. Theriogenology 2010;73:225-31.

[50] Tanghe S, Van Soom A, Sterckx V, Maes D, De Kruif A. Assessment of different sperm quality parameters to predict in vitro fertility of bulls. Reprod Domest Anim 2002;37:127-32.

[51] Hu JH, Zan LS, Zhao XL, Li QW, Jiang ZL, Li YK, et al. Effects of trehalose supplementation on semen quality and oxidative stress variables in frozen-thawed bovine semen. J Anim Sci 2010;88: 1657-62.

[52] Sariözkan S, Bucak MN, Tuncer PB, Ulutaş PA, Bilgen A. The influence of cysteine and taurine on microscopic-oxidative stress parameters and fertilizing ability of bull semen following cryopreservation. Cryobiology 2009;58:134-8.

[53] Rao TKS, Kumar N, Patel NB, Chauhan I, Chaurasia S. Sperm selection techniques and antioxidant fortification in low grade semen of bulls: review. Vet World 2013;6:579-85.

[54] Maia MS, Bicudo SD. Radicais livres, antioxidantes e função espermática em mamíferos: uma revisão. Rev Bras Reprod Anim 2009;33: 183-93.

[55] O’Flaherty CM, Beorlegui NB, Beconi MT. Reactive oxygen species requirements for bovine sperm capacitation and acrosome reaction. Theriogenology 1999;52:289-301.

[56] Gonçalves FS, Barretto LSS, Arruda RP, Perri SHV, Mingoti GZ. Effect of antioxidants during bovine in vitro fertilization procedures on spermatozoa and embryo development. Reprod Domest Anim 2010; 45:129-35.

[57] Alvarenga MA, Papa FO, Carmo MT, Kievitsbosch T, Chaves MMBC, Ramires Neto C. Methods of concentrating stallion semen. J Equine Vet Sci 2012;32:424-9.

[58] Sudano MJ, Crespilho AM, Fernandes CB, Martins Junior A, Papa FO, Rodrigues J, et al. Use of Bayesian inference to correlate in vitro embryo production and in vivo fertility in zebu bulls. Vet Med Int 2011:2011:1-6.

[59] Katska L, Ryńska B, Smorag Z. Effect of seminal plasma on the in vitro fertilizability of bull spermatozoa. Anim Reprod Sci 1996;44 23-31.

[60] Moura AA, Souza CE, Stanley BA, Chapman DA, Killian GJ. Proteomics of caudaepididymal fluid from mature Holstein bulls. J Proteomics 2010;73:2006-20.

[61] Rodríguez-Martínez H, Kvist U, Ernerudh J, Sanz L, Calvete JJ. Seminal plasma proteins: what role do they play? Am J Reprod Immunol 2011;66:11-22.

[62] Juyena NS, Stelletta C. Seminal plasma: an essential attribute to spermatozoa. J Androl 2012;33:536-51.

[63] Stinshoff $H$, Krienke M, Ekhlasi-Hundrieser M, Wilkening S, Hanstedt A, Frese D, et al. Seminal plasma and seminal plasma proteins added to bulk sorted sperm do not alter the mRNA expression of in vitro produced bovine embryos. Theriogenology 2012;78:132-9.

[64] Somfai T, Bodó S, Nagy S, Papp ÁB, Iváncsics J, Baranyai B, et al. Effect of swim up and Percoll treatment on viability and acrosome integrity of frozen-thawed bull spermatozoa. Reprod Domest Anim 2002;37:285-90.

[65] Samardzija M, Karadjole M, Matkovic M, Cergolj M, Getz I, Dobranic T, et al. A comparison of BoviPure ${ }^{\circledR}$ and Percoll ${ }^{\circledR}$ on bull sperm separation protocols for IVF. Anim Reprod Sci 2006;91:237-47.

[66] Machado GM, Carvalho JO, Siqueira Filho E, Caixeta ES, Franco MM Rumpf R, et al. Effect of Percoll volume, duration and force of centrifugation, on in vitro production and sex ratio of bovine embryos. Theriogenology 2009;71:1289-97.

[67] Zúccari CESN, Carrijo PR, Leite PA, Scaldelai PRR, Rodovalho NCM, Zanenga CA, et al. Seleção em gradiente de Percoll ${ }^{\circledR}$ sobre os parâmetros espermáticos do sêmen bovino congelado. Ver Bras Saúde E Produção Anim 2008;9:358-66.

[68] Carvalho JO, Sartori R, Machado GM, Mourão GB, Dode MAN. Quality assessment of bovine cryopreserved sperm after sexing by flow cytometry and their use in in vitro embryo production. Theriogenology 2010;74:1521-30.

[69] Silva PFN, Gadella BM. Detection of damage in mammalian sperm cells. Theriogenology 2006;65:958-78.

[70] Bordignon V, Smith LC. Ultraviolet-irradiated spermatozoa activate oocytes but arrest preimplantation development after fertilization and nuclear transplantation in cattle. Biol Reprod 1999;61: 1513-20.

[71] Fatehi AN, Bevers MM, Schoevers E, Roelen BAJ, Colenbrander B, Gadella BM. DNA damage in bovine sperm does not block fertilization and early embryonic development but induces apoptosis after the first cleavages. J Androl 2006;27:176-88. 